\title{
Production cost of ice slurry using a saline solution and different ice mass fractions, applied to "Perico" (Coryphaena Hippurus) artisanal fishing in Peru
}

\author{
Juan José Milón Guzmán ${ }^{1, *}$, Sergio Leal Braga ${ }^{2}$, Herbert Jesús del Carpio Beltrán ${ }^{1}$, Mario Enrique Díaz Coa ${ }^{1}$ \\ ${ }^{1}$ Universidad Tecnológica del Perú, Peru \\ ${ }^{2}$ Pontifícia Universidade Católica do Rio de Janeiro, Brazil
}

\begin{abstract}
An experimental study was carried out to determine the production costs of ice slurry, using a saline solution with different fractions of ice, for "Perico" (Coryphaena Hippurus) artisanal fishing in the Peruvian sea. A 3-kW ice slurry generator, portable enough to fit in an artisanal boat, was used. The prototype was instrumented with sensors for temperature, density, and electrical parameters (voltage, current, power) measurement in order to determine the ice mass fraction and production costs. The results indicated that not only ice slurry ensures a higher cooling speed and less damage to the product, but also, its production costs are lower compared to flake ice.
\end{abstract}

\section{Introduction}

"Perico" (Coryphaena hippurus) is the second largest artisanal fishing resource in Peru, and an important export product [1]. After its capture, the conservation of this product through its journey to reach its final consumer is ensured by storing it in ice. However, this technology does not guarantee the innocuity and integrity of marine foods for a long time. During storage in these conditions, bacteria develops and the fish visual appearance deteriorates: its skin undergoes noticeable changes, like the loss of its shine and the thickening of the viscous layer that surrounds it, and their eyes wrinkle and sag [2] [3]. The storage of ice on boats requires a lot of space and, in artisanal fishing, the means used for this objective are not adequate. Ice is stored in drawers, containers or warehouses that do not ensure the necessary sanitary conditions to avoid the contamination of fish. Since its skin is soft and easily damaged, storing fish on ice exposes it to rough conditions that can cause the contamination of its meat with bacteria [4].

For this reason, researchers searched for new techniques that could solve these problems and found a solution in ice slurry. This fluid is composed of microparticles of ice in an aqueous solution [5] and has better thermo-physical characteristics compared to other preservation techniques, such as solid ice. It has a higher heat exchange capacity and allows for better physical preservation of fish: it slows down the degradation and oxidation of fish and makes its handling more hygienic. Different studies have concluded that ice slurry reduces the growth of microbes in seafood, and that it also extends its shelf life, allowing consumers to enjoy marine products in good conditions [6] [7].

\subsection{Ice Slurry}

Ice slurry is made of ice microcrystals suspended in an aqueous solution. It is produced using a formulation of water and a solute (sodium chloride, sugar, alcohol, propylene glycol, ethylene glycol, mainly) [8]. The concentration of the solute determines the phase change temperature. The amount of ice produced (ice mass fraction) depends on the generator and the type of evaporator. Usually, ice mass fractions range between 5 and $35 \%$. Ice slurry, as a secondary refrigerant can be used directly or indirectly, depending on the process. Different research studies have been carried out experimenting an ice slurry flow in pipes with different ice mass fractions [9] [10] [11] [12] [13].

Another important line of research developed in recent years is the study of the thermophysical properties of aqueous solutions and ice slurry [14] [15]. In direct cooling applications, different studies have been carried out, especially for seafood [16] [3] [17] [7]. The most common technology used to generate ice slurry is the scraper tube system, however, other studies propose improving the process, for example, using inclined cavities that would provide greater force for the generation of ice slurry [18], using intermittent operation generators [19] or with numerical simulation techniques [20].

Even though different studies have been done on ice slurry and its properties for seafood cooling, no literature has been found regarding the production costs of ice slurry with different ice mass fractions for artisanal fishing applications.

\section{Experimental Model}

Corresponding author: jmilon@utp.edu.pe 
The experimental model is made up of the ice slurry generator and the parameter measurement and acquisition system. This equipment was provided by the Technological University of Peru (Fig. 1).

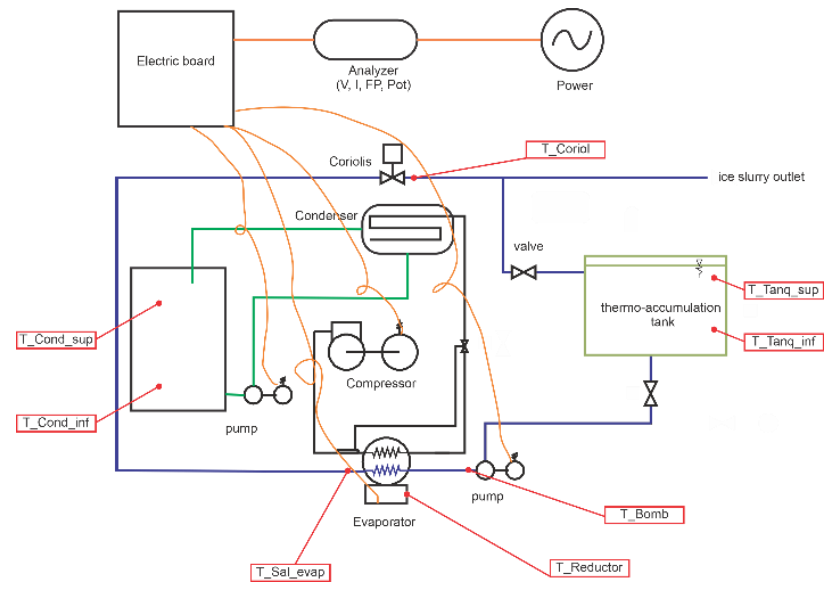

Fig. 1. Diagram of the experimental model.

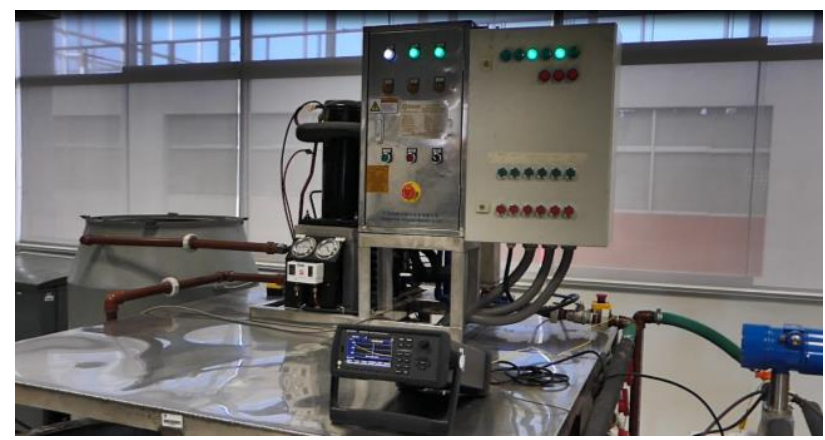

Fig. 2. Experimental model.

The ice slurry generator is a scraper type that works with a scraper helicoid and a gear motor. It weighs $250 \mathrm{~kg}$ and works with a water condenser, suitable for installation in artisanal fishing boats. It can produce up to 1 ton of ice slurry per day, which is sent to a storage tank. The generator's average consumption is $3 \mathrm{~kW}$. Its dimensions and weight are adequate for its installation on board the "Perico" artisanal fishing boat.

In order to measure the temperature, $0.5 \mathrm{~mm}$-diameter K-type Teflon ${ }^{\circledR}$-coated thermocouples, were used. To= measure the density of ice slurry, a Coriolis-type meter= was used. A Power Quality Analyzer was installed as well.= It recorded the energy demand directly on the equipment= (voltage, current, power, harmonics).

\subsection{Experimental procedure}

In this phase, the experiments were carried out with a $3.6 \%$ (mass/mass) aqueous solution of sodium chloride, varying the ice mass fraction. The ice mass fractions considered were between $1 \%$ and $35 \%$, since higher ice mass fractions generate vibrations in the generator, reaching viscosity limits that impede ice slurry pumping.

\subsection{Determination of the ice mass fraction}

Ice Slurry is made up of ice microcrystals suspended in an aqueous solution. At the beginning of the process, the aqueous solution (water and salt) is prepared, this aqueous solution is in a liquid state, that is, in a single phase. When the cooling process starts and the aqueous solution reaches the phase change temperature, microcrystals of ice are formed. From this point there are two phases: solid (ice microcrystals) and liquid (carrier fluid: liquid water and salt). As the ice mass fraction increases, the salt concentration in the carrier fluid also increases, this phenomenon causes the phase change temperature to drop as well.

Table 1. Ice mass fraction determination.

\begin{tabular}{|c|c|}
\hline Parameter & Calculation \\
\hline Energy [W h] & $\mathrm{E}=\mathrm{P} \times \mathrm{t}$ \\
\hline Stored energy [W h] & $\mathrm{Ea}=\sum_{E(n-1)}^{E n} E$ \\
\hline Generation cost & Cost $=\mathrm{Ea} \times \mathrm{USD} /(\mathrm{W} \mathrm{h})$ \\
\hline Ice mass fraction [15] & $x_{h}=\frac{\rho_{h}}{\rho_{i s}}\left(\frac{\rho_{f p}-\rho_{i s}}{\rho_{f p}-\rho_{h}}\right)$ \\
\hline Ice density [14] & $\begin{array}{l}\rho_{h} \\
=A 1+A 2 T+A 3 T^{2}\end{array}$ \\
\hline Ice slurry density & Coriolis \\
\hline $\begin{array}{l}\text { Carrier fluid (water and } \\
\text { salt) density [15] }\end{array}$ & $\begin{array}{l}\text { Salt concentration } \\
\text { Phase change } \\
\text { temperature }\end{array}$ \\
\hline
\end{tabular}

Where

$\mathrm{E}=$ Energy $[\mathrm{W} \mathrm{h}][\mathrm{J}]$

$\mathrm{P}=$ Power $[\mathrm{W}]$

$\mathrm{t}=$ Time

$\mathrm{Ea}=$ Stored energy $[\mathrm{W} \mathrm{h}]$

Cost $=$ Monetary value of energy $[\mathrm{PEN}]$

$\mathrm{x}_{\mathrm{h}}=$ Ice mass fraction $[\mathrm{kg} / \mathrm{kg}]$

$\rho_{\mathrm{h}}=$ Ice density $\left[\mathrm{kg} / \mathrm{m}^{3}\right]$

$\rho_{\mathrm{fp}}=$ Carrier fluid density $\left[\mathrm{kg} / \mathrm{m}^{3}\right]$

$\rho_{\text {is }}=$ Ice slurry density $\left[\mathrm{kg} / \mathrm{m}^{3}\right]$

\section{Results and analysis}

Figure 3 shows the variation of voltage, frequency, current and power factor with respect to time. All these parameters were measured and recorded by the network analyzer. It can be seen that all the parameters remain almost constant during the experiment. On average, the voltage remained at $218 \mathrm{~V}$, the frequency at $60.1 \mathrm{~Hz}$. The power factor varied between 0.97 to 0.98 , and the current varied from $14.1 \mathrm{~A}$ to $15.1 \mathrm{~A}$. The current changed since the higher the ice mass fraction, the higher the energy the compressor requires (due to the phase change temperature).

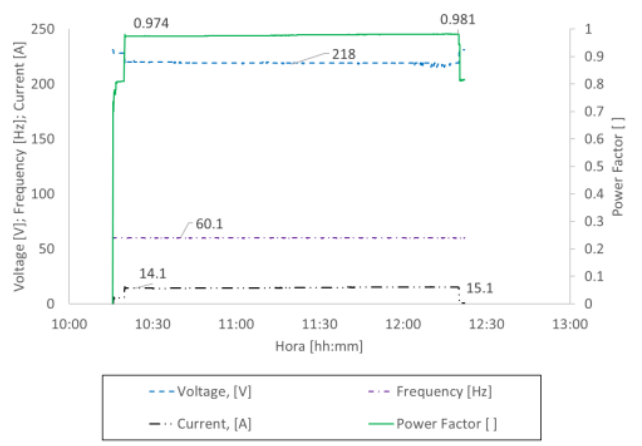

Fig. 3. Electrical parameters. 
Figure 4 shows the variation of electrical power over time. The electrical power rises with the rising salt concentration in the carrier fluid and the rising ice mass fraction.

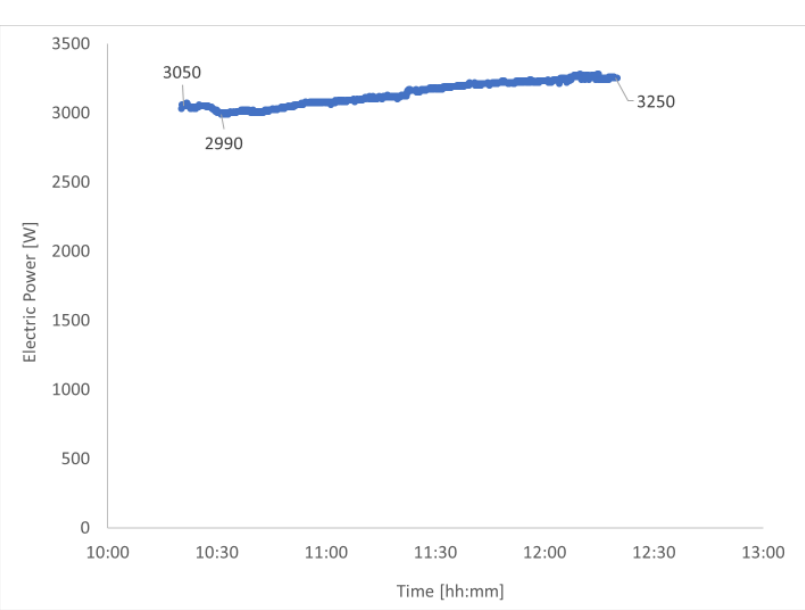

Fig. 4. Electrical power.

Figure 5 shows the variation in ice slurry temperature and density. It can be seen that the phase change occurs at a temperature of $-1.46{ }^{\circ} \mathrm{C}$ and that this temperature decreases until it reaches the value of $-1.86{ }^{\circ} \mathrm{C}$. The density of ice slurry varies between $1025 \mathrm{~kg} / \mathrm{m}^{3}$ and 996 $\mathrm{kg} / \mathrm{m}^{3}$. Although the density decreases, the ice concentration increases and, at high ice concentrations, ice slurry cannot flow through the pipe system and through the hydraulic pump.

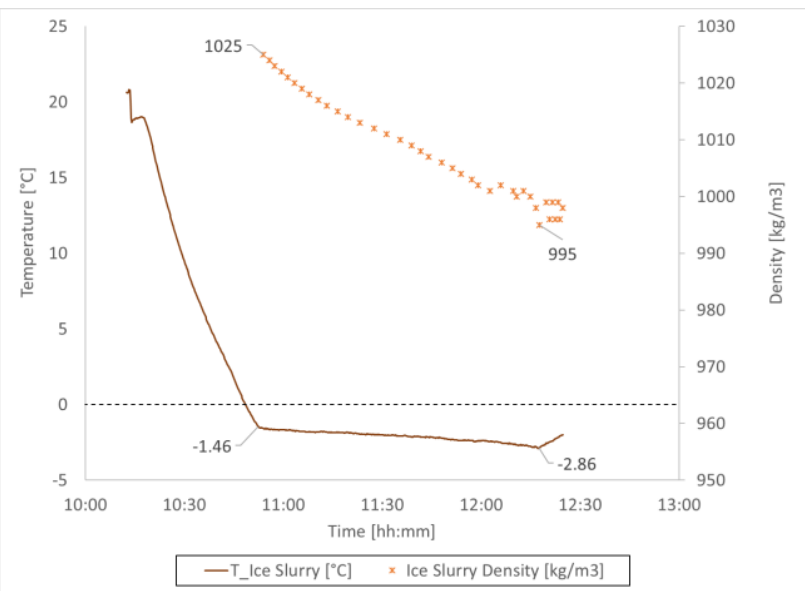

Fig. 5. Temperature and density of ice slurry.

Figure 6 shows the variation of the density of the carrier fluid and the ice slurry. Before the beginning of the formation of the first ice crystal, the density of the carrier fluid was increasing. At the moment of phase change the density fell and began to rise again due to the increase in the salt concentration in the carrier fluid. The density of the ice slurry dropped considerably until the Coriolis sensor revealed an error in the measurement (when the ice mass fraction was very high and did not flow through the meter). Finally, it can be seen that the density of the ice remained almost constant throughout the phase change.

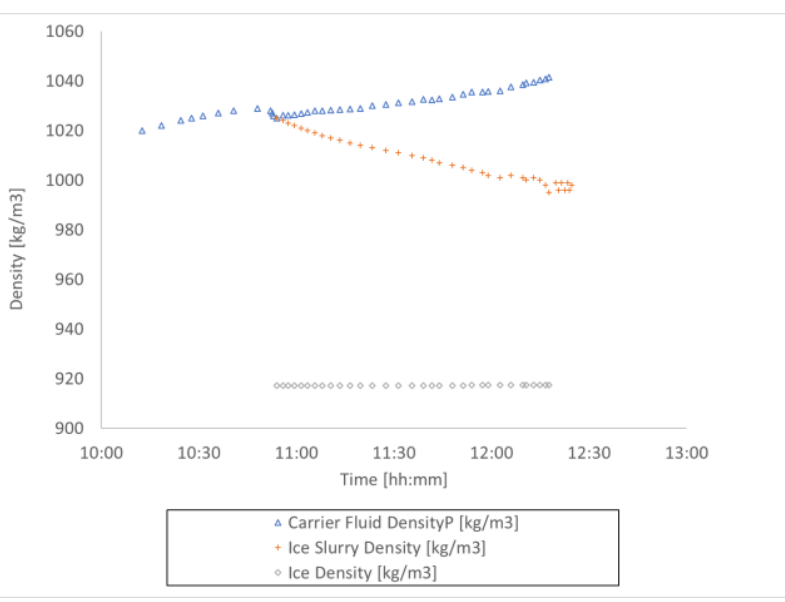

Fig. 6. Density of ice slurry components.

Figure 7 shows the variation in density as a function of the ice mass fraction, from the beginning of the phase change. Figure 8 shows the variation in the ice mass fraction as a function of the temperature of the ice slurry. The decrease of the phase change temperature indicates that the ice mass fraction is increasing. It should be considered that these temperature and density values correspond to an initial concentration of $3.6 \%$ of salt in water, this value being very similar to the one measured in the Peruvian sea.

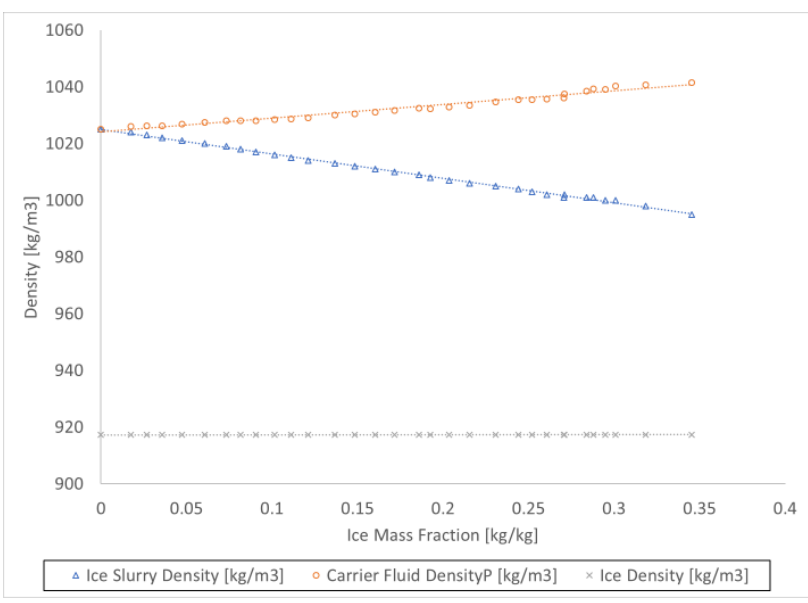

Fig. 7. Density as a function of ice mass fraction.

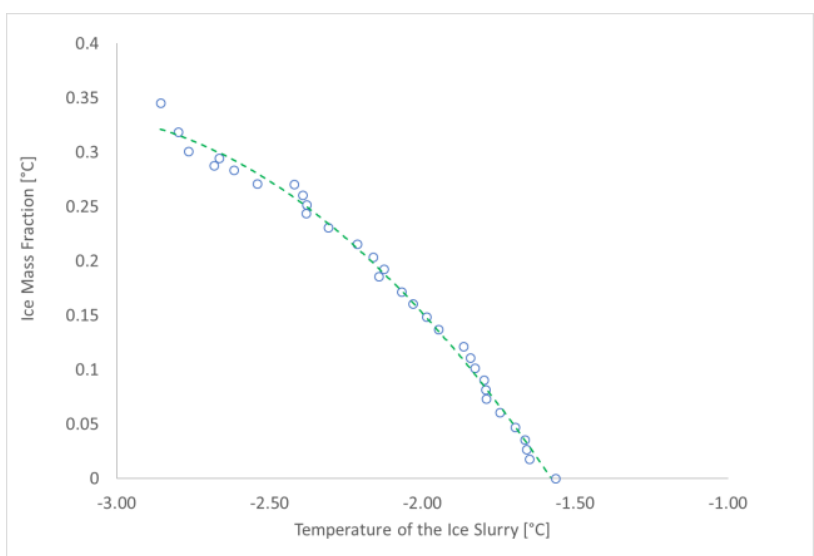

Fig. 8. Ice mass fraction as a function of phase change temperature. 
Figure 9 shows the costs per unit of mass as a function of the ice mass fraction. The higher the ice mass fraction, the higher the production costs. However, the ice mass fraction cannot exceed $35 \%$ due to the flow properties of the ice slurry that impede its circulation through the piping system. These production costs constitute a slight advantage over conventional systems (flake ice) for cooling fish: ice slurry is produced from sea water and can be produced exactly at the needed quantity. This allows savings, avoiding costs mainly due to transportation and storage.

These results are important for artisanal fishermen who currently use flake ice and could switch to ice slurry produced from seawater, saving on transportation and storage in the vessel.

The costs of flake ice range between $55 \mathrm{USD} /$ ton and $75 \mathrm{USD} /$ ton, depending on the demand. These values become $70 \mathrm{USD} /$ ton and $100 \mathrm{USD} /$ ton when considering transportation to the fishing zone (between 7 and 15 days). In comparison, the cost of ice slurry production would be $65 \mathrm{USD} /$ ton at a $30 \%$ ice mass fraction, taking into account the fact that there is no transportation cost since it is generated offshore when required.

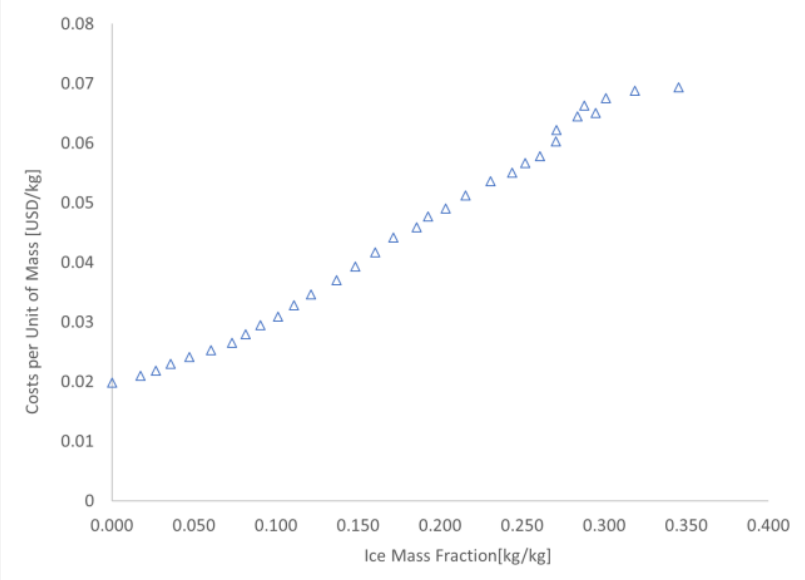

Fig. 9. Ice slurry production costs at different ice mass fractions.

\section{Conclusions}

Ice slurry is an efficient cooling system that can be applied directly to artisanal fishing products and can be produced from sea water. The ice mass fraction is an important parameter that determines the cooling speed and the need for fluid renewal during the transportation of the product until it reaches port. In this research study, the production costs of ice slurry with different ice mass fractions has been calculated, which allows a detailed estimation of the costs of seafood conservation on the high seas and in any other seafood artisanal transportation process. It is important to emphasize that nowadays artisanal fishing in Peru is dominated by the use of flake ice as a means of conservation for "Perico". This causes product losses due to product damage and poor conservation conditions because of inappropriate storage temperatures. The use of ice slurry would represent an improvement in the artisanal fishing process, increasing the income of fishermen and improving their quality of life.

\section{References}

1. R. Gozzer Wuest, "EL Perico, la segunda pesquería artesanal del Perú," OCEANA, Protegiendo los Océanos del Mundo, 5 Abril 2017.

2. N. Belletti, "Tecnologies de Conservació de Peix i Marisc," Centre de Noves Tecnologies i processos alimentans, Mercabarna, 2010.

3. C. Piñero, J. Barros Velázquez and P. Aubourg, "Effects of newer slurry ice systems on the quality of aquatic food products: a comparative review versus flake-ice chilling methods," Trends in Food Science \& Tecnology, vol. 15, no. 12, pp. 575-582, 2004.

4. M. Shawyer and A. F. Medina Pizzali, "El uso de hielo en pequeñas embarcaciones de pesca," $F A O$ Documento Técnico de Pesca, no. 436, p. 120, 2005.

5. C. Hagg, "Ice Slurry as Secondary Fluid in Refrigeration Systems," KTH Industrial Engineering and Management, vol. V, no. 48, 2005.

6. C. Campos, O. Rodriguez, V. Losada and S. Aubourg, "Effects of storage in ozonised slurry ice on the sensory and microbial quality of sardine (Sardina pilchardus)," International Journal of Food Microbiology, no. 103, pp. 121-130, 2005.

7. B. Zhang, S. Deng, M. Gao and J. Chen, "Effect of slurry ice on the functional properties of proteins related to quality loss during skipjack tuna (Katsuwonus pelamis) chilled storage," J. Food Sci, vol. 80, no. 4, pp. 695-702, 2015.

8. M. Kauffeld, M. Kawaji and P. W. Egolf, Handbook on Ice Slurries, Paris: International Institute of Refrigeration, 2005.

9. R. F.A, Yanuar and P. A.S, "Effect of ice mass fraction on ice slurry flow for cold energy storage application," Energy Reports, vol. 6, no. 2, pp. 790794, 2020.

10. J. P. Bedécarrats, F. Strub and C. Peuvrel, "Thermal and hydrodynamic considerations of ice slurry in heat exchangers," International journal of refrigeration, no. 32, pp. 1791-1800, 2009.

11. J. Wang, S. Wang, T. Zhang and F. Battaglia, "Numerical and analytical investigation of ice slurry isothermal flow through horizontal bends," International Journal of Refrigeration, vol. 92, pp. 37-54, 2018.

12. H. Kumano, T. Kobayashi, Y. Makino, T. Morimoto and T. Asaoka, "Experimental study on flow characteristics of ice slurry through a Tjunction Part I: Laminar flow," International Journal of Refrigeration, vol. 116, pp. 89-95, 2020.

13. J. Chen, J. Huang, S. Deng and Y. Huang, "Combining ozone and slurry ice to maximize shelf-life and quality of bighead croaker (Collichthys niveatus)," J Food Sci Technol, vol. 53, no. 10, pp. 3651-3660, 2016. 
14. A. Melinder and E. Granryd, "Using property values of aqueous solutions and ice to estimate ice concentrations an enthalpies of ice slurries," International Journal of Refrigeration, vol. 28, pp. 13-19, 2005.

15. Melinder, "Properties and other aspects of aqueous solutions used for single phase and ice slurry applications," International Journal of Refrigeration, no. 33, pp. 1506 - 1512, 2010.

16. W. Chun-hua, Y. Chun-hong and Y. Xing-qian, “A Critical Review on Superchilling Preservation Technology in Aquatic Product," Journal of Integrative Agriculture, vol. XIII, no. 12, pp. 27882806, 2014

17. M. S. Gozzi, M. L. Piacente, V. Cruces and E. G. Díaz, "Influencia de la Temperatura de Conservación sobre la Formación de Histamina en Caballa (Scomber japonicus)," Inf. Tecnol, vol. 22, no. 6, pp. 53-62, 2011.
18. V. K. Tiwari and A. Kumar, "Enhancing ice slurry generation by using inclined cavity for subzero cold thermal energy storage: Simulation, experiment and performance analysis," Energy, vol. 183, pp. 398-414, 2019.

19. A. Kumar, S. K. Yadav, A. Mahato and A. Kumar, "On-demand intermittent ice slurry generation for subzero cold thermal energy storage: Numerical simulation and performance analysis," Applied Thermal Engineering, vol. 161, 2019.

20. K. Suzuki, T. Kawasaki, T. Asaoka and M. Yoshino, "Numerical simulations of solid-liquid and solid-solid interactions in ice slurry flows by the thermal immersed boundary-lattice Boltzmann method," International Journal of Heat and Mass Transfer, vol. 157, 2020. 